\title{
Heterochromatin reprogramming in rabbit embryos after fertilization, intra-, and inter-species SCNT correlates with preimplantation development
}

\author{
Cai-Xia Yang ${ }^{1,2,3,+}$, Zichuan Liu ${ }^{1,2,3, \neq}$, Renaud Fleurot ${ }^{1,2}$, Pierre Adenot ${ }^{1,2}$, \\ Véronique Duranthon $^{1,2}$, Xavier Vignon ${ }^{1,2}$, Qi Zhou ${ }^{3}$, Jean-Paul Renard ${ }^{1,2}$ \\ and Nathalie Beaujean ${ }^{1,2}$
}

${ }^{1}$ INRA, UMR 1198 Biologie du Developpement et Reproduction, F-78350 Jouy en Josas, France, ${ }^{2}$ ENVA, F-94704 Maisons Alfort, France and ${ }^{3}$ State Key Laboratory of Reproductive Biology, Institute of Zoology, Chinese Academy of Sciences, 100080 Beijing, People's Republic of China

Correspondence should be addressed to N Beaujean at INRA, UMR 1198 Biologie du Developpement et Reproduction; Email: nathalie.beaujean@jouy.inra.fr

${ }^{\dagger} \mathrm{C}-\mathrm{X}$ Yang is now at Department of Animal Science and Center for Integrated Animal Genomics, lowa State University, Ames 50011, lowa, USA

${ }^{\ddagger} \mathrm{Z}$ Liu is now at Friedrich Miescher Institute for Biomedical Research, Maulbeerstrasse 66, CH-4058 Basel, Switzerland

\begin{abstract}
To investigate the embryonic genome organization upon fertilization and somatic cell nuclear transfer (SCNT), we tracked HP1 $\beta$ and CENP, two well-characterized protein markers of pericentric and centromeric compartments respectively, in four types of embryos produced by rabbit in vivo fertilization, rabbit parthenogenesis, rabbit-to-rabbit, and bovine-to-rabbit SCNT. In the interphase nuclei of rabbit cultured fibroblasts, centromeres and associated pericentric heterochromatin are usually isolated. Clustering into higher-order chromatin structures, such as the chromocenters seen in mouse and bovine somatic cells, could not be observed in rabbit fibroblasts. After fertilization, centromeres and associated pericentric heterochromatin are quite dispersed in rabbit embryos. The somatic-like organization is progressively established and completed only by the 8/16-cell stage, a stage that corresponds to major embryonic genome activation in this species. In SCNT embryos, pericentric heterochromatin distribution typical for rabbit and bovine somatic cells was incompletely reverted into the 1-cell embryonic form with remnants of heterochromatin clusters in $100 \%$ of bovine-to-rabbit embryos. Subsequently, the donor cell nuclear organization was rapidly re-established by the 4-cell stage. Remarkably, the incomplete remodeling of bovine-to-rabbit 1-cell embryos was associated with delayed transcriptional activation compared with rabbit-to-rabbit embryos. Together, the results confirm that pericentric heterochromatin spatio-temporal reorganization is an important step of embryonic genome reprogramming. It also appears that genome reorganization in SCNT embryos is mainly dependent on the nuclear characteristics of the donor cells, not on the recipient cytoplasm.
\end{abstract}

Reproduction (2013) 145 149-159

\section{Introduction}

Somatic cell nuclear transfer (SCNT) has obtained success in many kinds of mammals. However, the low efficiency associated with development both in intraand inter-species SCNT is still the major obstacle to its widespread application (Dominko et al. 1999, Sansinena et al. 2002, Arat et al. 2003, Chang et al. 2003, 2004, Ikumi et al. 2004, Lorthongpanich et al. 2008, Song et al. 2009, Hong et al. 2012, Kwon et al. 2011). SCNT involves fundamental questions about differentiation and its reversibility. After being introduced into recipient oocytes, differentiated somatic nuclei must be completely remodeled to initiate another round of embryonic development. Although the abnormal chromatin remodeling has been implicated as primary reasons for the low efficiency of the SCNT procedure (Arat et al. 2003, Park et al. 2004, Wang et al. 2009), the associated mechanisms have not been completely elucidated. In order to obtain a deeper insight into these events, we focused on centromeric and pericentric heterochromatin, known to form higher-order chromatin structures within nuclei in the interphase.

Indeed, numerous studies have addressed the nuclear organization of centromeric and pericentric chromosome regions in somatic cycling cells (Haaf \& Schmid 1989, 1991, Weierich et al. 2003, Solovei et al. 2004). In mouse interphase somatic nuclei, pericentric 
heterochromatin from several different chromosomes tends to aggregate into clusters called chromocenters, which are surrounded by the centromeres from the chromosomes involved in their formation (Hsu et al. 1971, Haaf \& Schmid 1991, Cerda et al. 1999, Guenatri et al. 2004). Such chromocenters can also be observed in bovine fibroblasts (Martin et al. 2006a, Pichugin et al. 2010), but not in human or rabbit cells. In human cells, pericentromeric heterochromatin is predominantly found in specific nuclear domains associated with centromeric regions called pericentromeres (Hayakawa et al. 2003). However, these domains do not seem to cluster, which may be because of the varieties of repeat sequences comprised in human pericentromeric regions (Lee et al. 1997). Similarly, computational approaches in rabbit 8-cell and blastocyst nuclei revealed that centromeres form regularly spaced patterns, thereby suggesting the presence of isolated pericentromeres in this species as in human cells (Andrey et al. 2010).

In mouse cells, chromocenters represent the major heterochromatin regions and play important roles in the regulation of gene expression (Brown et al. 1999, Francastel et al. 1999, Schübeler et al. 2000, Skok et al. 2001, Guenatri et al. 2004). Remarkably, in mouse embryos, we observed that these regions adopt a peculiar 'cartwheel' organization after fertilization characterized by the positioning of pericentric regions to the periphery of the nucleolus precursor bodies (NPBs; Martin et al. 2006a). This configuration has been suggested to maintain transcriptional silencing during parental genome maturation (Probst et al. 2007). Reorganization of these heterochromatin regions into 'chromocenters' occurs during the second cell stage, concomitantly with the major phase of major embryonic genome activation (EGA) in this species (Martin et al. 2006a, Probst et al. 2007). Remarkably, interference with pericentromeric transcription disturbs chromocenter formation and results in developmental arrest (Probst et al. 2010, Santenard et al. 2010).

In bovine, we observed a switch of pericentric heterochromatin distribution in fertilized embryos only at the 8-cell stage, at the time of EGA in this species (Martin et al. 2006a, Pichugin et al. 2010). Similarly, in rabbit, major EGA also takes place at the 8- to 16-cell stage (Manes 1973). However, as rabbit 8-cell and blastocyst nuclei do not present chromocenter-like structures but only isolated pericentromeres (Andrey et al. 2010), we questioned whether early rabbit embryos would present an embryonic-specific nuclear architecture (as in the two other species studied so far) and whether pericentromeres would form only at EGA. We therefore tracked HP1 $\beta$ and CENP, two wellcharacterized protein markers of the pericentric and centromeric compartments respectively.

Interestingly, in mouse and bovine cloned embryos obtained by nuclear transfer (NT), pericentric heterochromatin is rapidly reorganized to adopt an embryonic-like nuclear architecture (Martin et al. 2006b, Merico et al. 2007, Maalouf et al. 2009, Pichugin et al. 2010). However, reprogramming after NT is not perfect and aberrations are quite frequent: remains of somatic-like chromocenters, for example, are often observed (Martin et al. 2006b, Maalouf et al. 2009, Pichugin et al. 2010). In bovine NT embryos obtained from fibroblasts, we could also observe a premature compaction of pericentric heterochromatin at the 2- to 4-cell stages, i.e. much earlier than in the fertilized embryos (Pichugin et al. 2010).

We therefore also analyzed the dynamics of HP1 $\beta$ and CENP in early embryos reconstructed by intra-species SCNT. Then, we tested the reprogramming ability of rabbit oocytes on bovine donor cells characterized by the presence of large chromocenters (inter-species SCNT). Finally, we addressed whether heterochromatin remodeling was associated with the onset of transcriptional activity in these embryos.

\section{Results \\ Nuclear distribution of HP1 $\beta$ and CENP differs in mouse, rabbit, and bovine somatic cells}

To clarify centromeric and pericentric heterochromatin organization in rabbit and bovine fibroblasts (used as donor cells in the present study), we first analyzed the nuclear distributions of HP1 $\beta$ and centromere-specific CENP proteins in these two kinds of primary cultured fibroblasts in comparison with mouse NIH-3T3 established cell line. As expected, in mouse interphase nuclei, HP1 $\beta$-enriched pericentric heterochromatin was clustered, forming chromocenters, and each chromocenter was surrounded by several centromeres (Fig. 1, upper panel). We observed a similar organization in bovine fibroblasts (Fig. 1, lower panel); conversely, no chromocenters were observed in rabbit fibroblasts (Fig. 1, middle panel). In rabbit interphase nuclei, HP1 $\beta$ was diffusely distributed in the nucleoplasm with discrete accumulations that were quite small compared with mouse and bovine chromocenters. These HP1 $\beta$ foci were often associated with single centromeres (1:1 ratio), and occasionally single centromeres without HP1 $\beta$ association were observed. Furthermore, $40.2 \pm 2.9$ CENP dots on average were observed in interphase rabbit fibroblasts $(n=10)$, which correlated with the number of chromosomes in rabbits (44). This distribution pattern of pericentric heterochromatin and centromeres in rabbit cells is clearly similar to the pericentromeres observed in human cells (Hayakawa et al. 2003).

\section{Compaction of pericentric and centromeric compartments in rabbit fertilized embryos and parthenotes is associated with major EGA}

Next, we assessed the spatio-temporal distribution of HP1 $\beta$ and centromeres in early rabbit embryos obtained 

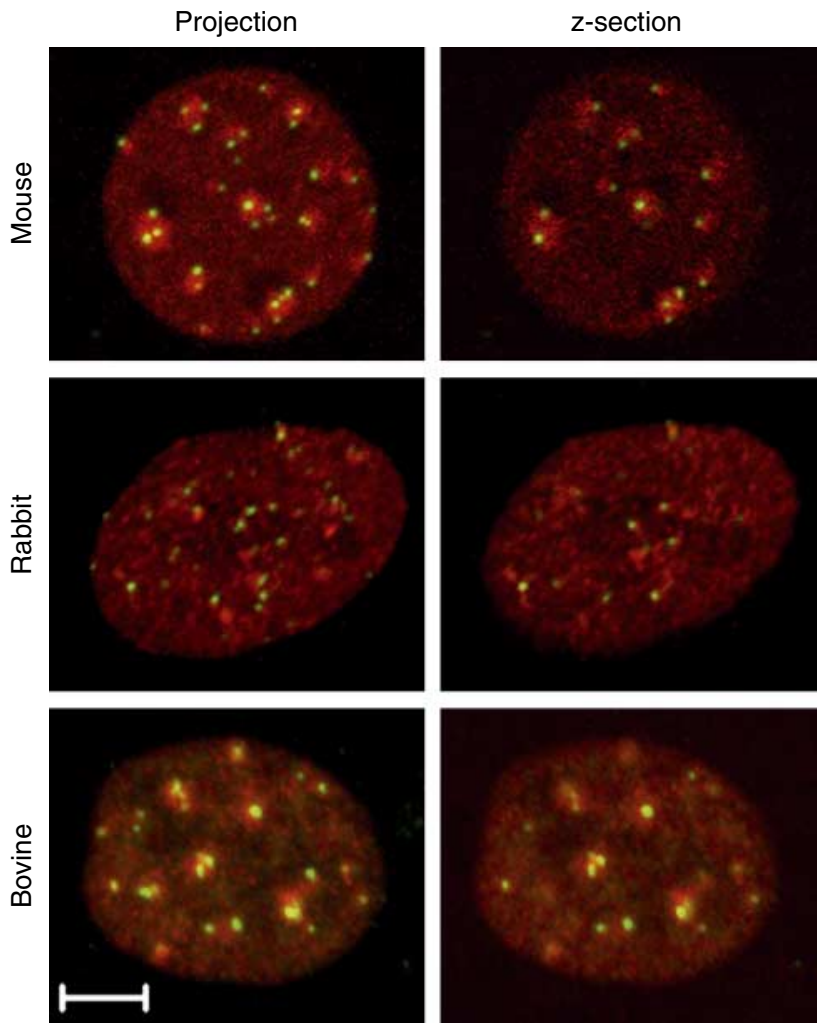

Figure 1 Immunostaining of HP1 $\beta$ (red) and CENP (green) in mouse, rabbit, and bovine somatic cells. Scale bars: $5 \mu \mathrm{m}$. (Upper panel) Mouse NIH-3T3 cell. (Middle panel) Rabbit fibroblast. (Lower panel) Bovine fibroblast. The left column represents maximum projections of confocal Z-stacks. The right column represents confocal single sections. In mouse and bovine interphase nuclei, HP1 $\beta$-enriched pericentric heterochromatin was clustered into chromocenters, and each chromocenter was surrounded by several centromeres (green). In contrast, interphase rabbit nuclei showed diffusely distributed HP1 $\beta$ in the nucleoplasm with discrete accumulations that were quite small compared with mouse and bovine chromocenters, and HP1 $\beta$ foci were often associated with single centromeres.

after natural fertilization to investigate when the somatic-like organization would be established during preimplantation development (Fig. 2). In 1-cell rabbit embryos, the female pronucleus ( $\mathrm{fPN}$ ) is usually smaller than the male one (mPN), whatever the time point analyzed (Reis Silva et al. 2011). At 19 hphCG ( 7 hpi), we observed that HP1 $\beta$ was diffused in the nucleoplasm of both $\mathrm{mPN}$ and $\mathrm{PPN}$, with no enrichment at the peripheries of any NPB (Flechon \& Kopecny 1998). Only a more brightly stained nucleoplasmic region adjoining the NPB was observed in the fPN (42 of 50 embryos; Fig. 2). After quantification, we found around 40 bright CENP dots in both PNs $(n=27)$, of which $27.5 \%$ were associated with NPBs, while the other ones were dispersed in the nucleoplasm (Table 1). At $22 \mathrm{hphCG}$ ( 10 hpi, late 1-cell; Fig. 2), the number of centromeres associated with NPBs decreased (in mPN only) as well as the total number of NPBs (Table 1). As a result, the total percentage of centromeres associated with NPBs dropped dramatically from $27.5 \%$ at 19 hphCG to $17 \%$ at 22 hphCG. These results in rabbit 1-cell embryos are very different from mouse in which NPBs seem to play a major role in attracting both pericentromeric heterochromatin and centromeres to form a 'cartwheel' (Martin et al. 2006a).

Upon cleavage to 2 -cell (Fig. 2), HP1 $\beta$ was still quite diffused in the nucleoplasm, also few HP1 $\beta$ foci appeared usually not associated with any CENP dot (15 of 21 embryos; Table 2). Nearly all CENP dots were clearly partitioned on one side of the nuclei as in mouse and bovine embryos (Martin et al. 2006a). At the 4-cell stage, more HP1 $\beta$ foci were observed in all embryos ( $n=18$; Figs 2 and 3 ) and CENP dots started to associate with them (6 of 18 embryos; Table 2). Subsequently, more prominent accumulations of HP1 $\beta$ appeared in the nucleoplasm, most probably by the clustering of smaller foci (Fig. 3). These accumulations were mostly associated with one centromere and the number of single isolated centromeres clearly decreased at the early 8/16-cell stage (Fig. 2). The typical somatic-like organization into pericentromeres was completely established at the late 8/16-cell stage (Figs 2 and 3), which correlates with major EGA in this species (Manes 1973).

In parallel, we analyzed the distribution of these two markers, HP1 $\beta$ and CENP, in rabbit diploid embryos derived from parthenogenesis to evaluate the impact of the activation protocol later used for NT (Fig. 4, left column). At the 1-cell stage, the organization of pericentric and centromeric heterochromatin was similar to the one described above in fertilized 1-cell embryos. The foci of HP1 $\beta$ that are associated with centromeres appeared at the 4-cell stage (Fig. 4, left column). In addition, centromeres tend to distribute in one part of the nucleus during the 2- and 4-cell stages. The typical somatic-like organization was established at the 8/16-cell stage, although HP1 $\beta$ foci remained quite smaller (Fig. 3) compared with fertilized embryos. Taken together, these data show that a similar spatio-temporal reorganization of pericentric and centromeric regions is recapitulated at the early stages of rabbit parthenotes and fertilized embryos.

\section{After rabbit intra-species SCNT, somatic nuclear organization is disrupted but compact foci of peri- centric heterochromatin reappear before 8-cell}

We next wondered whether rabbit NT embryos derived from somatic nuclei would adopt the somatic or embryonic type of nuclear organization. To address this question, the distribution of HP1 $\beta$ and CENP was observed in rabbit-to-rabbit SCNT embryos.

In 1-cell SCNT embryos fixed at $8 \mathrm{hpf}(n=35)$, the pronucleus-like structure formed contained uniform HP1 $\beta$ labeling in the nucleoplasm in $80 \%$ of embryos (Fig. 4, middle column), whereas the other $20 \%$ displayed some condensed HP1 $\beta$ accumulations (image not 

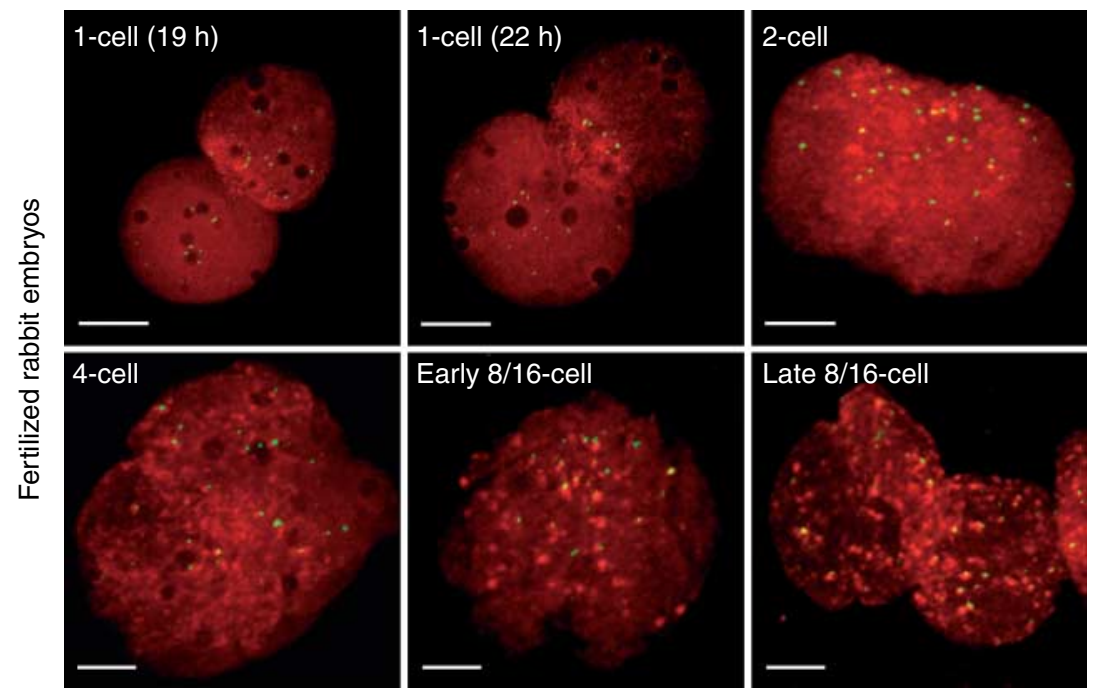

Figure 2 Immunostaining of HP1 $\beta$ (red) and CENP (green) in rabbit naturally fertilized embryos (maximum projections of confocal Z-stacks) at the 1 -cell (19 and 22 hphCG), 2-cell, 4-cell, early 8/16-cell, and late 8/16-cell stages. Scale bars: $5 \mu \mathrm{m}$. Only one nucleus per stage is shown but all blastomeres had similar staining within the embryos. shown, Table 2). In these embryos, we counted 37.5 \pm 3.9 CENP dots, of which $11.1 \%$ were organized at the NPB periphery (Fig. 4 and Table 1). These data show that after SCNT, the different components of somatic pericentromeres were rapidly reorganized into an embryonic type in the majority of 1-cell embryos.

In 2-cell SCNT embryos ( $15 \mathrm{hpf}, n=32), \mathrm{HP} 1 \beta$ was still diffusely distributed in the nucleoplasm in $59 \%$ of embryos (image not shown) but $41 \%$ displayed discrete accumulation of HP1 $\beta$ dots (Fig. 4), which were sometimes already linked with centromeres $(13 \%$ of embryos; Table 2).

Upon cleavage to 4-cell ( $n=35$; Fig. 4), most embryos showed somatic-like pericentromeres with compact pericentric and centromeric heterochromatin, i.e. 1 -cell cycle earlier than in rabbit fertilized embryos (Table 2). In total, $85 \%$ of the 4-cell embryos (30 of 35; Fig. 4) displayed pericentromeres: in each of the four nuclei $(31 \%)$, in three nuclei $(34 \%)$, or in two nuclei (20\%). The remaining nuclei (and embryos) had a similar nuclear organization to fertilized embryos (image not shown). HP1 $\beta$ foci were also more numerous in SCNT embryos than in fertilized ones (Fig. 3). We also observed that in vitro development of these rabbit SCNT embryos was not disturbed until the 4-cell stage and dramatically decreased thereafter (Table 3). Altogether these observations suggest that, although rabbit recipient oocytes can trigger nuclear remodeling of rabbit somatic donor cells, this process is insufficient.

\section{Bovine nuclei can be remodeled by rabbit oocytes after SCNT to some extent but typical bovine chromocenters are then rapidly re-established}

We then addressed the problem of epigenetic memory in inter-species SCNT and questioned whether pericentromeric heterochromatin and centromeres in embryos derived from bovine fibroblasts would adopt the donor species-type (bovine) or recipient species-type (rabbit) nuclear organization.

At the 1-cell stage in bovine-to-rabbit SCNT embryos (Fig. 4, last column), $100 \%$ of the embryos $(n=32$; Table 2 ) presented partially condensed HP1 $\beta$ foci mainly in the nucleoplasm and, in a few cases, on NPBs. Furthermore, the number of NPBs $(\sim 6.4 \pm 3.5)$ was significantly lower than that in rabbit-to-rabbit 1-cell

Table 1 Distribution of NPBs and CENP in 1-cell rabbit in vivo fertilized embryos, rabbit-to-rabbit SCNTembryos, and bovine-to-rabbit SCNTembryos.

\begin{tabular}{|c|c|c|c|c|c|c|c|}
\hline Stage & $\begin{array}{l}\text { Timing } \\
\text { (no. of } \\
\text { embryos) }\end{array}$ & $\begin{array}{l}\text { CENP dots } \\
\text { associated } \\
\text { with NPBs }\end{array}$ & $\begin{array}{c}\text { Total } \\
\text { CENP dots }\end{array}$ & $\begin{array}{c}\text { Percentage of } \\
\text { CENP dots } \\
\text { associated with } \\
\text { NPBs }\end{array}$ & $\begin{array}{l}\text { No. of } \\
\text { NPBs with } \\
\text { CENP dots }\end{array}$ & $\begin{array}{l}\text { Total no. } \\
\text { of NPBs }\end{array}$ & $\begin{array}{c}\text { Percentage } \\
\text { of NPBs with } \\
\text { CENP dots }\end{array}$ \\
\hline \multirow[t]{2}{*}{ Fertilized 1-cell mPN only } & 19 hphCG (27) & $7.1 \pm 3.0^{\mathrm{a}}$ & $18.7 \pm 1.7^{\mathrm{a}}$ & $37.7 \pm 16.4^{\mathrm{a}}$ & $5.6 \pm 2.3^{\mathrm{a}}$ & $9.3 \pm 1.7^{\mathrm{a}}$ & $61.5 \pm 26.2^{\mathrm{a}}$ \\
\hline & 22 hphCG (23) & $2.3 \pm 1.8^{b}$ & $18.1 \pm 2.3^{\mathrm{a}}$ & $12.4 \pm 9.8^{\mathrm{b}}$ & $2.1 \pm 1.6^{\mathrm{b}}$ & $7.2 \pm 2.9^{b}$ & $27.9 \pm 19.1^{\mathrm{b}}$ \\
\hline \multirow{2}{*}{ Fertilized 1-cell fPN only } & 19 hphCG (27) & $3.8 \pm 1.8^{\mathrm{a}}$ & $20.7 \pm 1.5^{\mathrm{a}}$ & $18.4 \pm 8.3^{\mathrm{a}}$ & $2.9 \pm 1.3^{\mathrm{a}}$ & $7.4 \pm 1.8^{\mathrm{a}}$ & $40.7 \pm 16.9^{a}$ \\
\hline & 22 hphCG (23) & $4.2 \pm 2.0^{\mathrm{a}}$ & $19.9 \pm 1.6^{\mathrm{a}}$ & $21.0 \pm 9.9^{\mathrm{a}}$ & $3.4 \pm 1.5^{\mathrm{a}}$ & $6.4 \pm 1.5^{b}$ & $54.1 \pm 22.2^{b}$ \\
\hline \multirow[t]{2}{*}{ Fertilized 1-cell mPN +fPN } & 19 hphCG (27) & $10.9 \pm 3.7^{\mathrm{a}}$ & $39.5 \pm 2.3^{\mathrm{a}}$ & $27.5 \pm 9.1^{\mathrm{a}}$ & $8.5 \pm 2.5^{\mathrm{a}}$ & $16.7 \pm 2.5^{\mathrm{a}}$ & $51.5 \pm 15.1^{\mathrm{a}}$ \\
\hline & 22 hphCG (23) & $6.6 \pm 3.0^{b}$ & $38.0 \pm 2.5^{\mathrm{a}}$ & $17.2 \pm 7.7^{\mathrm{b}}$ & $5.5 \pm 2.2^{b}$ & $13.7 \pm 3.5^{\mathrm{b}}$ & $41.0 \pm 15.7^{b}$ \\
\hline Rabbit-to-rabbit SCNT 1-cell & $8 \mathrm{hpf}(35)$ & $4.3 \pm 3.1^{\mathrm{c}}$ & $37.5 \pm 3.9^{\mathrm{d}}$ & $11.1 \pm 8.3^{\mathrm{d}}$ & $3.3 \pm 2.4^{\mathrm{d}}$ & $11.0 \pm 4.3^{\mathrm{e}}$ & $29.0 \pm 16.6^{\mathrm{e}}$ \\
\hline Bovine-to-rabbit SCNT 1-cell & $8 \mathrm{hpf}(32)$ & $4.9 \pm 3.9^{\mathrm{c}}$ & $52.8 \pm 4.3^{\mathrm{e}}$ & $9.7 \pm 4.7^{\mathrm{d}}$ & $2.8 \pm 1.9^{\mathrm{d}}$ & $6.4 \pm 3.5^{f}$ & $52.8 \pm 27.1^{f}$ \\
\hline
\end{tabular}

Statistical comparisons were performed i) within the fertilized 1-cell stage for mPN and fPN separately, ii) between the early and late 1-cell ( $\mathrm{mPN}+$ fPN), and iii) between SCNT embryos. Values with different superscript letters within the same column are significantly different $(P<0.05)$. Each value corresponds to the mean \pm s.E.M. 
Table 2 HP1 $\beta$ distribution in early rabbit in vivo fertilized embryos, rabbit-to-rabbit SCNT embryos, and bovine-to-rabbit SCNT embryos.

\begin{tabular}{|c|c|c|c|c|c|}
\hline Type of embryo & Stage & $\begin{array}{l}\text { Total no. } \\
\text { of embryos }\end{array}$ & $\begin{array}{c}\text { No. of embryos with uniform } \\
\text { HP1 } \beta \text { distribution }(\%)\end{array}$ & $\begin{array}{c}\text { No. of embryos } \\
\text { with HP1 } \beta \text { foci }(\%)\end{array}$ & $\begin{array}{c}\text { No. of embryos with somatic- } \\
\text { like structures }(\%)\end{array}$ \\
\hline \multirow{3}{*}{ Fertilized } & 1-cell & 50 & $50(100)$ & 0 & 0 \\
\hline & 2-cell & 21 & $6(29)$ & $15(71)$ & 0 \\
\hline & 4-cell & 18 & 0 & $18(100)$ & $6(33)$ \\
\hline \multirow{3}{*}{ Rabbit-to-rabbit SCNT } & 1-cell & 35 & $28(80)$ & $7(20)$ & 0 \\
\hline & 2-cell & 32 & 19 (59) & $13(41)$ & $4(13)$ \\
\hline & 4-cell & 35 & 0 & $35(100)$ & $26(75)$ \\
\hline \multirow[t]{3}{*}{ Bovine-to-rabbit SCNT } & 1-cell & 32 & 0 & $32(100)$ & 0 \\
\hline & 2-cell & 25 & 0 & $25(100)$ & $3(12)$ \\
\hline & 4-cell & 26 & 0 & $26(100)$ & $26(100)$ \\
\hline
\end{tabular}

The first columns present a summary of the different patterns observed in fertilized and SNCT embryos after HP1 $\beta$ immunodetection (uniform vs foci). The presence of somatic-like structures (pericentromeres or chromocenters) is given in the last column.

SCNT ( $11.0 \pm 4.3, n=35$; Table 1). In bovine-to-rabbit 1-cell embryos, 52.8 \pm 4.3 CENP dots on average were observed, which correlated with the number of chromosomes in the bovine donor cells $(2 n=60) ; 9.7 \%$ of these CENP were located at the NPB periphery as in rabbitto-rabbit SCNT (Table 1).

At 2-cell, nucleoplasmic accumulations of HP1 $\beta$ associated with CENP dots already appeared in $12 \%$ of the embryos (3 of 25; Fig. 4; Table 2), as in intra-species SCNT. Surprisingly, $88 \%$ of the embryos (22 of 25 ; Fig. 4 ) had HP1 $\beta$ rims on NPBs, a phenomenon that we did not observe in the other types of embryos analyzed so far in this study.

In the 4-cell embryos ( $n=26$; Fig. 4$)$, these peri-NPB rims of HP1 $\beta$ disappeared while large nucleoplasmic HP1 $\beta$ foci appeared (Figs 3 and 4). The decrease in HP1 $\beta$ association with NPBs was not correlated with a decrease in NPB numbers, suggesting that HP1 $\beta$ actually dissociated from NPBs. Remarkably, $100 \%$ of the embryos displayed bovine-like chromocenters $(n=26$; Table 2): in all four nuclei $(65 \%)$, in three nuclei $(27 \%)$, or in two nuclei (8\%). Even in bovine-to-bovine SCNT, we never observed such a high percentage of abnormal heterochromatin distribution (Pichugin et al. 2010). This may be related to the fact that all reconstructed bovine-to-rabbit SCNT embryos arrested before the 8-cell stage (Table 3 ).

The fluorescence intensity profile of HP1 $\beta$ staining (Fig. 4, last panel) suggested that the size of HP1 $\beta$ foci in bovine-to-rabbit SCNT embryos was different from that of rabbit parthenotes and rabbit-to-rabbit SCNT embryos. Quantification confirmed that HP1 $\beta$ foci in bovineto-rabbit SCNT were 3.5 times larger at the 4-cell than in the 2-cell embryos (Fig. 3).

Altogether it suggests that donor cells maintain an epigenetic memory of their original nuclear status that determines pericentric and centromeric reorganization after NT.

\section{Global transcriptional activation is delayed in early 1-cell embryos derived from bovine-to-rabbit SCNT}

Next, we questioned whether incomplete remodeling in bovine-to-rabbit SCNT embryos could be associated with abnormal transcriptional activity. Although we did not observe differences at the time of major EGA (all embryos were transcriptionally active, data not shown), we noticed differences at the 1-cell stage when transcriptional activity starts, i.e. when minor EGA takes place (Memili \& First 1999). Very weak signals of BrUTP incorporation were observed only in $9.2 \%$ of bovine-to-rabbit SCNT embryos at $5 \mathrm{hpf}$, which was significantly lower than in rabbit-to-rabbit SCNT embryos (36.7\%; Table 4). At $10 \mathrm{hpf}$, the percentage significantly increased to $71.4 \%$ and reached 85 and $97.8 \%$ at the 2 -cell stage, at 13 and $17 \mathrm{hpf}$ respectively. However, it was not statistically different
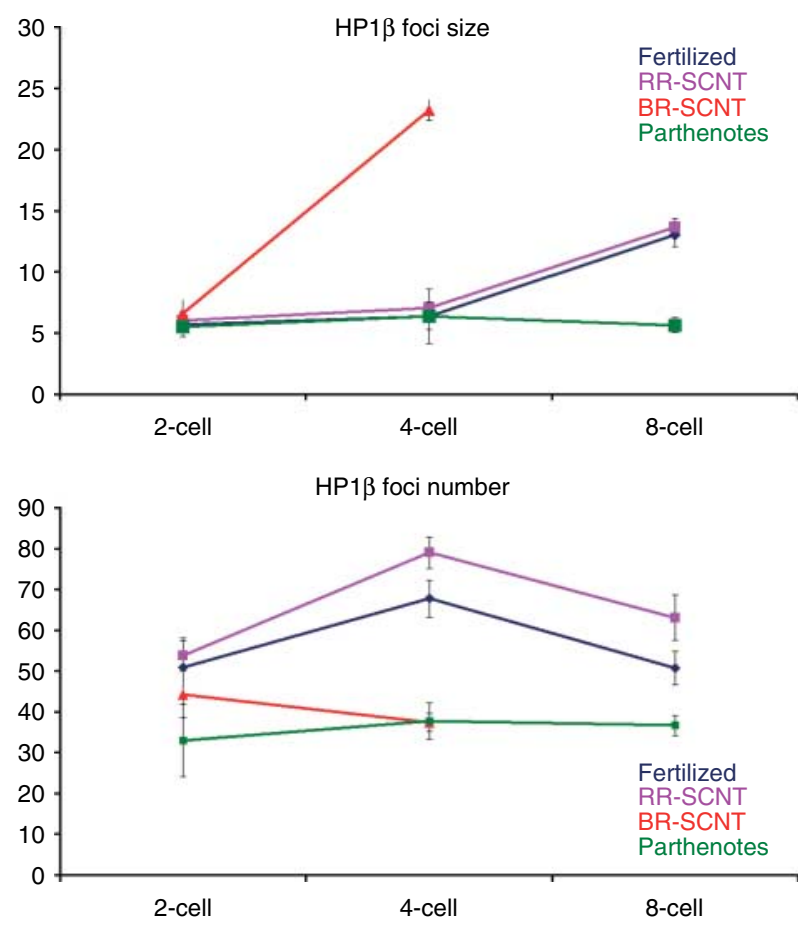

Figure 3 Graphs showing computational quantification of HP1 $\beta$ foci number and mean size within the nuclei of parthenotes, fertilized embryos, rabbit-to-rabbit (RR) SCNT, and bovine-to-rabbit (BR) SCNT, from 2- to 8-cell (except for BR-SCNT embryos that did not develop beyond the 4-cell stage). Errors bars correspond to S.E.M. 

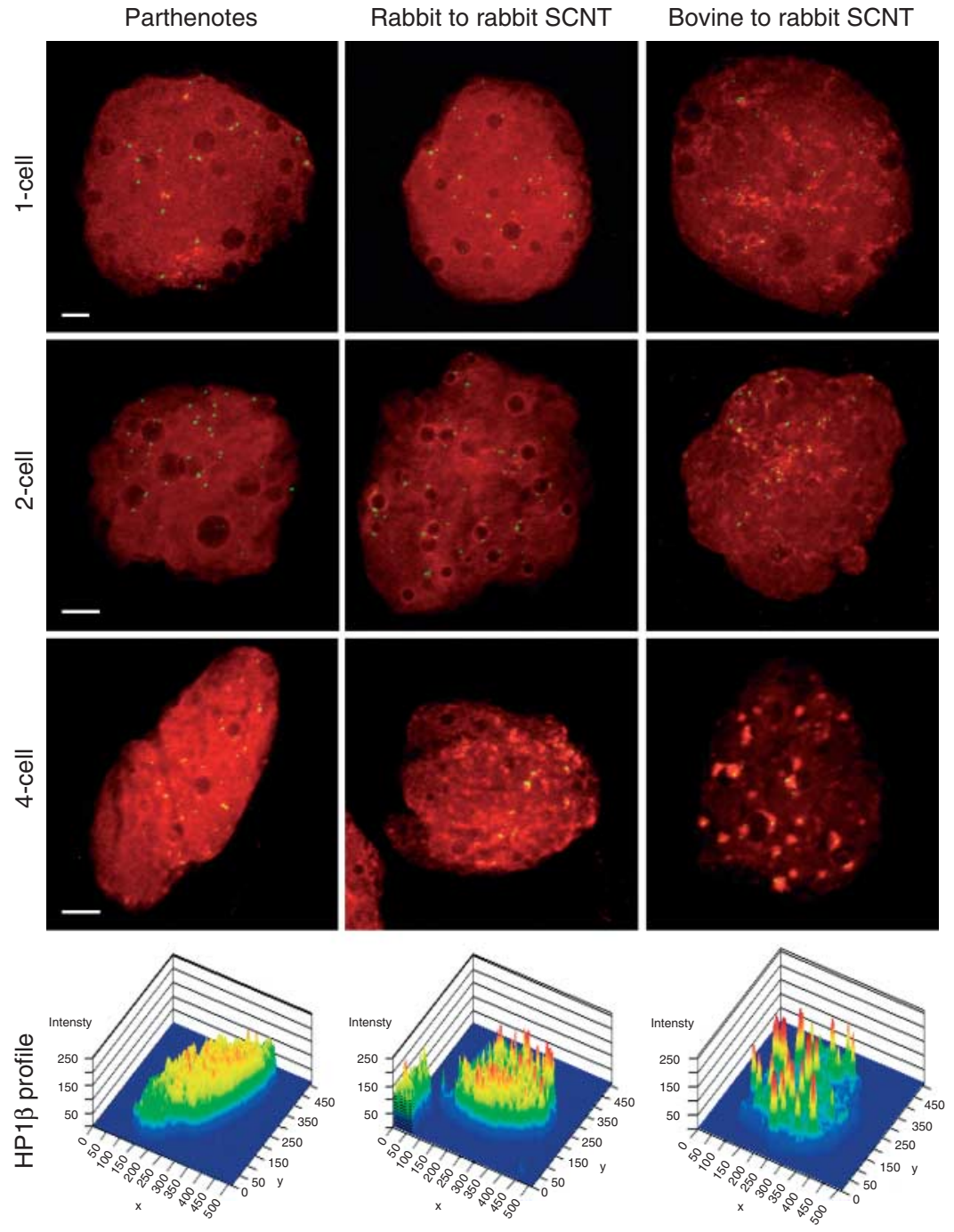

Figure 4 Maximum projections of confocal Z-stacks presenting HP1 $\beta$ (red) and CENP (green) distributions in rabbit parthenogenetically activated embryos, rabbit-to-rabbit SCNT embryos, and bovine-to-rabbit SCNT embryos. The most representative images are shown. Scale bars: $5 \mu \mathrm{m}$. 1-, 2-, and 4-cellstage embryos are presented on the top, second, and third row of panels respectively. The bottom row of panels fluorescence intensity profile of HP1 $\beta$ in the 4-cell nuclei. from rabbit-to-rabbit SCNT embryos anymore (Table 4). This shows a delayed transcriptional activation in bovine-to-rabbit SCNT embryos at the early 1-cell stage, compared with rabbit intra-species SCNT embryos.

\section{Discussion}

In the present study, we show that the assembly of pericentric heterochromatin and centromeres in rabbit fibroblasts is different from that in mouse and bovine. In interphase mouse and bovine somatic nuclei, pericentric regions from different chromosomes are organized into chromocenters enriched in HP1 $\beta$ and each chromocenter is surrounded with several centromeres (Hsu et al. 1971, Haaf \& Schmid 1991, Cerda et al. 1999, Guenatri et al. 2004, Martin et al. 2006a, Pichugin et al. 2010). Differently, in rabbit somatic nuclei, individualized HP1 $\beta$ dots are associated with single centromere (1:1 ratio) as in human somatic nuclei (Hayakawa et al. 2003). The differences in genome organization among species probably result from the characteristic feature of satellite DNA repeats at

Table 3 In vitro developmental potential of fertilized, intra-, and inter-species SCNT embryos.

\begin{tabular}{|c|c|c|c|c|c|}
\hline Type of embryo & $\begin{array}{c}\text { No. of reconstructed } \\
\text { embryos }\end{array}$ & Fused $(\%)$ & 2- to 4-cell (\%) & Morula (\%) & Blastocyst (\%) \\
\hline Bovine-to-rabbit SCNT & 356 & $252(70.8)^{\mathrm{a}}$ & $213(84.5)^{\mathrm{a}}$ & $0^{\mathrm{a}}$ & $0^{\mathrm{a}}$ \\
\hline Rabbit-to-rabbit SCNT & 173 & $127(73.4)^{\mathrm{a}}$ & $108(85.0)^{a}$ & $49(38.6)^{b}$ & $37(29.1)^{\mathrm{b}}$ \\
\hline $\begin{array}{l}\text { Rabbit fertilized in vivo, } \\
\text { cultured in vitro }\end{array}$ & 165 & - & $153(92.7)^{\mathrm{a}}$ & $145(87.9)^{c}$ & $142(86.1)^{\mathrm{c}}$ \\
\hline
\end{tabular}

Values with different superscript letters within the same column are significantly different $(P<0.05)$. 
Table 4 Global transcriptional activity at 1-cell in rabbit-to-rabbit and bovine-to-rabbit SCNT embryos.

\begin{tabular}{lccc}
\hline & \multicolumn{3}{c}{ BrUTP incorporation: timing and number of positive embryos/total number $(\%)$} \\
\cline { 2 - 4 } Type of embryo & $5 \mathrm{~h} \mathrm{BrUTP}+/ \mathrm{n}(\%)$ & $10 \mathrm{~h} \mathrm{BrUTP}+/ \mathrm{n}(\%)$ & $13 \mathrm{~h} \mathrm{BrUTP}+/ \mathrm{n}(\%)$ \\
\hline Rabbit-to-rabbit embryos & $13 / 34(36.7 \pm 16.9)^{\mathrm{a}}$ & $21 / 23(92.5 \pm 6.6)^{\mathrm{a}}$ & $27 / 29(92.9 \pm 1.7)^{\mathrm{a}}$ \\
Bovine-to-rabbit embryos & $3 / 31(9.2 \pm 8.0)^{\mathrm{b}}$ & $27 / 38(71.4 \pm 15.3)^{\mathrm{a}}$ & $34 / 41(85.0 \pm 17.5)^{\mathrm{a}}$ \\
\hline
\end{tabular}

Values with different superscript letters within a column are significantly different $(P<0.05)$.

pericentric and centromeric regions. Three different families of human satellite sequences are indeed found in pericentromeres of different chromosomes (Miller \& Therman 2000), whereas mouse major satellites are quite conserved (Vissel \& Choo 1989). In rabbit, Ekes et al. (2004) identified two families of DNA repeat sequences: Rsat I and Rsat II that do not hybridize to every chromosome but are both localized in the centromeric regions of the chromosomes. It would therefore be interesting to perform fluorescent in situ hybridization with DNA probes directed against Rsat I and Rsat II both to evaluate i) whether these two families occupy distinct nuclear regions in somatic nuclei and ii) whether different chromosomes have similar dynamics or not during nuclear embryonic reorganization.

In rabbit embryos following fertilization, our results show that centromeres and associated pericentric heterochromatin are quite dispersed and the somaticlike organization is progressively established and completed only by the $8 / 16$-cell stage, a stage that corresponds to major EGA in this species. This is in agreement with previous studies showing striking coincidences between these two events in mouse and bovine embryos (Martin et al. 2006a, Pichugin et al. 2010). We also observed that this precise spatio-temporal reorganization of pericentromeric heterochromatin is disturbed in SCNT embryos. After the introduction of somatic cells, either from rabbit or bovine origin, into rabbit enucleated oocyte cytoplasm, the formation of pronucleus-like structures with the disruption of somatic heterochromatin clusters (pericentromeres and chromocenters respectively) was very rapid in both types of embryos. However, decondensation of HP1 $\beta$-labeled heterochromatin was incomplete in $20 \%$ rabbit-to-rabbit embryos and $100 \%$ bovine-to-rabbit embryos at the 1-cell stage. Also, compared with rabbit intra-species SCNT embryos, delayed transcriptional activation was observed at the early 1-cell stage in bovine-to-rabbit SCNT embryos. Furthermore, the reorganization of somatic-like/donor species-specific heterochromatin clusters took place more quickly than in fertilized embryos, at least 1-cell cycle earlier. We believe that these abnormalities may correlate with lower embryonic developmental potential. This hypothesis is supported by the fact that these abnormalities are observed just before major EGA and that most embryos get blocked at major EGA.

Remarkably, pericentromeric heterochromatin organization in inter-species SCNT embryos was mainly dependent on the donor cell organization, showing the presence of an 'epigenetic memory'. In contrast to rabbit-to-rabbit SCNT, we observed a lower proportion of embryos with transcriptional activity and a higher proportion of embryos with incompletely decondensed HP1 $\beta$ at the 1-cell stage. We also found that the re-establishment of compact heterochromatin at the 4-cell stage leads to the formation of large foci that resembled somatic chromocenters, suggesting that the nuclear remodeling of bovine nuclei in rabbit cytoplasm is less sufficient. One possible explanation is that inter-species nucleo-cytoplasmic compatibility between the introduced bovine genome and maternal rabbit factors present in the recipient oocytes is lower than that in the case of rabbit intra-species SNCT, probably because some remodeling factors are species-specific.

The mechanisms involved in heterochromatin formation are still subject to discussion. Recently, it has been shown in mouse embryos that, similarly to fission yeast and plants, transcripts generated by pericentromeric repeats would be processed to small RNAs that in turn guide heterochromatin formation (Probst et al. 2010, Santenard et al. 2010). It was also shown that the presence of histone variant $\mathrm{H} 3.3$ and low levels or absence of $\mathrm{H} 3 \mathrm{~K} 27$ methylation would provide a chromatin environment permissive for the transcription of pericentromeric chromatin, leading to heterochromatin formation at pericentromeric repeats (Santenard et al. 2010). Such data are not available yet in other species and further studies are required. It would be of particular interest to see whether the epigenetic memory of heterochromatin organization in the donor genome is based on one of these mechanisms.

In the present study, immunodetection of HP1 $\beta$ and CENP also reveals centromeres/chromocenters partitioning in one part of the nuclear volume in 2-cell fertilized rabbit, rabbit-to-rabbit SCNT, and bovine-to-rabbit SCNT embryos. This is in agreement with the description of nuclear partitioning in mouse and bovine early-stage embryos (Mayer et al. 2000, Martin et al. 2006b, Pichugin et al. 2010); a Rabl polarization of chromosomes that was first described in plant cells (Shaw et al. 2002). It suggests that in reconstructed SCNT embryos, the movements of chromosome territories (CTs) could occur as in fertilized ones. The first study dealing with CT distribution during major genome activation has recently been published in fertilized bovine embryos (Koehler et al. 2009). The authors have found that during 
the preimplantation period, a non-random radial CT arrangement is established but they do not have proof that this nuclear reorganization is a consequence or a cause of EGA. Looking at these CTs, large-scale movements in fertilized vs SCNT embryos would bring new insights to this question. As bovine-to-rabbit embryos do not develop beyond the 4-cell stage, it might indeed be that the large-scale movements leading to the Rabl-like orientation are not sufficient after SCNT.

\section{Materials and Methods Animals}

Animals were handled and used in accordance with the French legal requirements of animal care.

\section{Collection of rabbit oocytes and embryos}

Superovulation of mature New Zealand White female rabbits was induced by successive intramuscular injections of FSH (Stimufol, Mérial, France) given $12 \mathrm{~h}$ apart (Challah-Jacques et al. 2003). Female rabbits were then mated with vasectomized or normal males at $12 \mathrm{~h}$ after the last FSH injection and $30 \mathrm{IU}$ of human chorionic gonadotropin (hCG, Choluron; Intervet, Angers, France) were injected a few minutes after mating. MII oocytes or 1-cell embryos were recovered $16 \mathrm{~h}$ post-hCG injection (Christians et al. 1994, Challah-Jacques et al. 2003). The cumulus of MII oocytes was removed by exposure to $0.5 \%$ hyaluronidase (Sigma) for a few minutes followed by gentle pipetting, and then denuded oocytes were subjected to NT experiments. In vivo-derived zygotes, after the assessment of fertilization by the presence of two polar bodies, were in vitro cultured up to different experimental stages in $\mathrm{B} 2$ medium with $2.5 \%$ FCS (Sigma) in $5 \% \mathrm{CO}_{2}$ at $38.5{ }^{\circ} \mathrm{C}$. In rabbits, insemination normally occurs at $\sim 12 \mathrm{~h}$ post-hCG ( $t=0$ postinsemination, pi).

\section{Cell culture}

Mouse fibroblasts (3T3) were cultured in DMEM supplemented with L-glutamine and $10 \%$ newborn calf serum, incubated in $5 \% \mathrm{CO}_{2}$ at $37^{\circ} \mathrm{C}$. Bovine ear and rabbit fetal skin fibroblasts were cultured in DMEM with $15 \%$ FCS in $5 \% \mathrm{CO}_{2}$ at $38.5^{\circ} \mathrm{C}$. For immunofluorescence detection, cells were grown on coverslips to sub-confluence for about $24 \mathrm{~h}$.

\section{Nuclear transfer}

Rabbit oocytes without cumulus cells were enucleated according to our laboratory's routine protocol (Chesné et al. 2002, Challah-Jacques et al. 2003). Briefly, after 20 min culture in M199 medium containing 10\% FCS (M199-FCS) and $0.5 \mu \mathrm{g} / \mathrm{ml}$ Hoechst 33342, oocytes were placed into a micromanipulation chamber containing $0.5 \mu \mathrm{g} / \mathrm{ml}$ Hoechst 33342 and $7 \mu \mathrm{g} / \mathrm{ml}$ cytochalasin B (CB) in M199-FCS buffered with $20 \mathrm{mM}$ HEPES. Under the control of a video-enhanced camera at a low ultraviolet light level, metaphase II plate together with the first polar body $(\mathrm{PB})$ was removed. Bovine ear and rabbit fetal skin fibroblasts at three to ten passages were induced into the $\mathrm{G}_{0} / \mathrm{G}_{1}$ stage by serum starvation culture $(0.5 \%$ FCS) for 2-6 days and then used as nuclear donors. Cells were introduced into the subzonal space of enucleated oocytes. Cell-oocyte pairs were electrostimulated (3 DC of $3.2 \mathrm{kV} / \mathrm{cm}$ for $20 \mu \mathrm{s}$ each) with a BTX stimulator (Biotechnologies \& Experimental Research, Inc., San Diego, CA, USA) to induce fusion in $0.3 \mathrm{M}$ mannitol in distilled water containing $0.1 \mathrm{mM}$ $\mathrm{CaCl}_{2}$ and $0.1 \mathrm{mM} \mathrm{MgCl}$. One hour later, fused embryos were activated by a second set of pulses (same parameters as fusion) followed by $1 \mathrm{~h}$ incubation with $5 \mu \mathrm{g} / \mathrm{ml}$ cycloheximide and $2 \mathrm{mM}$ 6-dimethylaminopyridine in M199-FCS, and then were cultured in B2 medium supplemented with $2.5 \%$ FCS in a humidified atmosphere of $5 \% \mathrm{CO}_{2}$ at $38.5{ }^{\circ} \mathrm{C}$ up to different experimental stages.

For parthenogenesis, rabbit oocytes underwent a similar activation protocol except that they were then cultured $4 \mathrm{~h}$ in B2 medium supplemented with $7 \mu \mathrm{g} / \mathrm{ml} \mathrm{CB}$ in order to inhibit the extrusion of the second PB after electrostimulation.

\section{Immunofluorescence}

Rabbit fertilized embryos were collected at 7 and $10 \mathrm{hpi}$ (1-cell), 15 hpi (2-cell), 22 hpi (4-cell), 33 hpi (early 8/16-cell), and 40 hpi (late 8/16-cell). The collection of rabbit parthenogenetic embryos was performed at $8 \mathrm{~h}$ post-activation (hpa; 1-cell), 15 hpa (2-cell), and 22 hpa (4-cell). Rabbit-to-rabbit and bovine-to-rabbit SCNT embryos were collected at $8 \mathrm{hpf}$ (1-cell), $15 \mathrm{hpf}$ (2-cell), and $22 \mathrm{hpf}$ (4-cell) respectively. Two to four replicates were performed at each time point.

Collected embryos were processed for HP1 $\beta$ and CENP immunostaining as described previously (Pichugin et al. 2010). Briefly, after 20 min fixation at room temperature (RT) using $2 \%$ paraformaldehyde and $30 \mathrm{~min}$ permeabilization at RT using $0.5 \%$ Triton X-100, embryos were blocked for 45 min with $3 \%$ BSA in PBS. Incubation with primary antibodies was performed overnight at $4{ }^{\circ} \mathrm{C}$ before three washes with $0.05 \%$ Tween-20 in PBS (15 min each) followed by incubation with secondary antibodies (1 h, RT). Embryos were washed again and postfixed $10 \mathrm{~min}$ using $2 \%$ paraformaldehyde. For microscopic observation, embryos were mounted onto glass slides in Vectashield (Vector Laboratories, Les Ulis, France). HP1 $\beta$ was detected with a mouse monoclonal anti-HP1 $\beta$ antibody $(1: 250$ in 3\% BSA/PBS, clone 1 MOD 1A9; Euromedex, Souffelweyersheim, France), using a lissamine-rhodamine-conjugated antimouse secondary antibody (1:150 in 2\% BSA/PBS; Jackson ImmunoResearch, Interchim, France). The centromeres were labeled with a human CREST antibody that recognizes mostly CENPA (1:250 in 3\% BSA/PBS; Immunovision, Cellon Sarl, Luxembourg), using a FITC-conjugated anti-human secondary antibody (1:150 in 2\% BSA/PBS; Jackson ImmunoResearch). Rabbit, bovine, and mouse fibroblasts were grown on glass coverslips and then processed similarly.

\section{Assessment of global transcriptional activity in embryos}

Rabbit-to-rabbit and bovine-to-rabbit SCNT embryos were collected at $5 \mathrm{hpf}$ (early 1 -cell), $10 \mathrm{hpf}$ (late 1 -cell), $13 \mathrm{hpf}$ 
(early 2-cell), and $17 \mathrm{hpf}$ (late 4-cell) to detect transcriptional activity. Three replicates were done at each time point. Immunofluorescent detection of $\mathrm{BrU}$ incorporation into nascent RNA transcripts was performed, using BrUTP (Sigma) as a precursor. Embryos using the plasma permeabilized method were treated according to a previous report in mice (Aoki et al. 1997), except that: i) the plasma membrane of embryos was permeabilized for 3-5 min with $0.1 \%$ Triton $\mathrm{X}-100$ in 'physiological buffer' (PB); ii) BrUTP incorporation (working concentration, $1.6 \mathrm{mM}$ ) was performed for $30 \mathrm{~min}$ at $33{ }^{\circ} \mathrm{C}$; and iii) the nuclear membrane was permeabilized by a treatment using $0.4 \%$ Triton $\mathrm{X}-100$ in PB for 3 min. After fixation with $3.7 \%$ paraformaldehyde in $\mathrm{PB}$ overnight at $4{ }^{\circ} \mathrm{C}$, embryos were washed completely using PBS with $0.3 \%$ BSA and blocked $30 \mathrm{~min}$ in the same medium at RT. Incubation with the primary antibody (1:100 dilution, mouse monoclonal antiBrUTP antibody; Caltag Laboratories, Burlingame, CA, USA) was allowed to proceed overnight at $4{ }^{\circ} \mathrm{C}$ followed by three washes. Incubation with a FITC-conjugated anti-mouse secondary antibody (1:400 dilution; Sigma) was performed at RT for $1 \mathrm{~h}$. Nucleic acids were counterstained with PI $(50 \mu \mathrm{g} / \mathrm{ml})$ for $15 \mathrm{~min}$ at $37^{\circ} \mathrm{C}$. Embryos were mounted onto glass slides in Vectashield.

\section{Confocal microscopy}

All samples were scanned on a Zeiss LSM 510 confocal microscope (MIMA2 Platform; INRA) using a Plan-Apochromat $63 \times / 1.4$ oil objective. Imaging was performed with sequential multi-track scanning using 488 and $543 \mathrm{~nm}$ wavelength lasers separately. Complete Z-stacks were acquired using a frame size of $512 \times 512$ with a pixel depth of 8 bits and $0.37 \mathrm{~mm}$ Z-step. Images were prepared using Adobe Photoshop CS version.

\section{Image analysis}

Analysis of the fluorescence intensity profiles for HP1 $\beta$ was performed with the software LSM510 3.2 version. Manual counting of CENP dots and NPBs was performed with ImageJ software.

To determine HP1 $\beta$ foci size and number, automated 3D image processing and analysis were performed with the help of the ITK library (http://www.itk.org) interfaced with the Python script language (Lehmann 2006). Briefly, images were first automatically resized to a constant voxel size $(0.284 \times 0.284 \times$ $0.36 \mu \mathrm{m})$. Granules were then detected using an automatic threshold segmentation procedure: i) the regions of interest (ROI) of nuclei were determined by a threshold method largely used in astronomy which analyzed only the intensities of background and computed the intensity value (mean + sigma) as the lower threshold (Lehmann et al. 2006); ii) images were processed according to two different methods: the most intense granules were segmented following subtraction of a background image generated by a 3D median filtering, whereas a 2D top-hat filtering was applied to detect small and/or faint granules; and iii) these two segmented images were then combined and granule parameters in the nuclear ROI were determined.
To qualify the BrUTP incorporation signal, the embryo showing at least three clear staining dots in each interphase nucleus was referred to as positive transcription nucleus.

\section{Statistical analysis}

Comparison of the number of CENP dots and NPBs (nuclear precursor bodies) among 1-cell-stage embryos was done with the Wilcoxon-Mann-Whitney test. The cleavage rates as well as the percentage of embryos with positive transcription were compared using the $\chi^{2}$-test. Statistical significance was determined when the $P$ value was $<0.05$.

\section{Declaration of interest}

The authors declare that there is no conflict of interest that could be perceived as prejudicing the impartiality of the research reported.

\section{Funding}

The present work was supported by INRA Jeune Equipe funding, the French embassy in Beijing, and the MRI at INRA.

\section{Acknowledgements}

We are grateful to the platform MIMA2 (Microscopie et Imagerie des Microorganismes, Animaux et Elements) for confocal microscopy and UCEA for animal care. We would like to thank Sandrine Peron for the culture of bovine fibroblasts, Laurent Boulanger and Nathalie Daniel for the culture of rabbit fibroblasts, as well as Linda Maulny for the collection of rabbit oviducts.

\section{References}

Andrey P, Kiêu K, Kress C, Lehmann G, Tirichine L, Liu Z, Biot E, Adenot PG, Hue-Beauvais C, Houba-Hérin N et al. 2010 Statistical analysis of $3 \mathrm{D}$ images detects regular spatial distributions of centromeres and chromocenters in animal and plant nuclei. PLoS Computational Biology 6 e1000853. (doi:10.1371/journal.pcbi.1000853)

Aoki F, Worrad DM \& Schultz RM 1997 Regulation of transcriptional activity during the first and second cell cycles in the preimplantation mouse embryo. Developmental Biology 181 296-307. (doi:10.1006/ dbio.1996.8466)

Arat S, Rzucidlo SJ \& Stice SL 2003 Gene expression and in vitro development of inter-species nuclear transfer embryos. Molecular Reproduction and Development 66 334-342. (doi:10.1002/mrd.10362)

Brown KE, Baxter J, Graf D, Merkenschlager M \& Fisher AG 1999 Dynamic repositioning of genes in the nucleus of lymphocytes preparing for cell division. Molecular Cell 3 207-217. (doi:10.1016/S1097-2765(00) 80311-1)

Cerda MC, Berríos S, Fernández-Donoso R, Garagna S \& Redi C 1999 Organisation of complex nuclear domains in somatic mouse cells. Biologie Cellulaire 91 55-65. (doi:10.1111/j.1768-322X.1999.tb01084.x)

Challah-Jacques M, Chesne P \& Renard JP 2003 Production of cloned rabbits by somatic nuclear transfer. Cloning and Stem Cells 5 295-299. (doi:10.1089/153623003772032808)

Chang KH, Lim JM, Kang SK, Lee BC, Moon SY \& Hwang WS 2003 Blastocyst formation, karyotype, and mitochondrial DNA of interspecies 
embryos derived from nuclear transfer of human cord fibroblasts into enucleated bovine oocytes. Fertility and Sterility 80 1380-1387. (doi:10.1016/j.fertnstert.2003.07.006)

Chang KH, Lim JM, Kang SK, Lee BC, Moon SY \& Hwang WS 2004 An optimized protocol of a human-to-cattle interspecies somatic cell nuclear transfer. Fertility and Sterility 82 960-962. (doi:10.1016/ j.fertnstert.2004.03.052)

Chesné P, Adenot PG, Viglietta C, Baratte M, Boulanger L \& Renard JP 2002 Cloned rabbits produced by nuclear transfer from adult somatic cells. Nature Biotechnology 20 366-369. (doi:10.1038/nbt0402-366)

Christians E, Rao VH \& Renard JP 1994 Sequential acquisition of transcriptional control during early embryonic development in the rabbit. Developmental Biology 164 160-172. (doi:10.1006/dbio.1994.1188)

Dominko T, Mitalipova M, Haley B, Beyhan Z, Memili E, McKusick B \& First NL 1999 Bovine oocyte cytoplasm supports development of embryos produced by nuclear transfer of somatic cell nuclei from various mammalian species. Biology of Reproduction 60 1496-1502. (doi:10.1095/biolreprod60.6.1496)

Ekes C, Csonka E, Hadlaczky G \& Cserpán I 2004 Isolation, cloning and characterization of two major satellite DNA families of rabbit (Oryctolagus cuniculus). Gene 343 271-279. (doi:10.1016/j.gene.2004.09.029)

Fléchon JE \& Kopecný V 1998 The nature of the 'nucleolus precursor body' in early preimplantation embryos: a review of fine-structure cytochemical, immunocytochemical and autoradiographic data related to nucleolar function. Zygote 6 183-191. (doi:10.1017/S09671994 98000112)

Francastel C, Walters MC, Groudine M \& Martin DI 1999 A functional enhancer suppresses silencing of a transgene and prevents its localization close to centrometric heterochromatin. Cell 99 259-269. (doi:10.1016/S0092-8674(00)81657-8)

Guenatri M, Bailly D, Maison C \& Almouzni G 2004 Mouse centric and pericentric satellite repeats form distinct functional heterochromatin. Journal of Cell Biology 166 493-505. (doi:10.1083/jcb.200403109)

Haaf T \& Schmid M 1989 Centromeric association and non-random distribution of centromeres in human tumor cells. Human Genetics $\mathbf{8 1}$ 137-143. (doi:10.1007/BF00293889)

Haaf T \& Schmid M 1991 Chromosome topology in mammalian interphase nuclei. Experimental Cell Research 192 325-332. (doi:10.1016/00144827(91)90048-Y)

Hayakawa T, Haraguchi T, Masumoto H \& Hiraoka Y 2003 Cell cycle behavior of human HP1 subtypes: distinct molecular domains of HP1 are required for their centromeric localization during interphase and metaphase. Journal of Cell Science 116 3327-3338. (doi:10.1242/jcs.00635)

Hong SG, Oh HJ, Park JE, Kim MJ, Kim GA, Koo OJ, Jang G \& Lee BC 2012 Production of transgenic canine embryos using interspecies somatic cell nuclear transfer. Zygote 20 67-72. (doi:10.1017/ s0967199410000651)

Hsu TC, Cooper JE, Mace ML Jr \& Brinkley BR 1971 Arrangement of centromeres in mouse cells. Chromosoma 34 73-87. (doi:10.1007/ BF00285517)

Ikumi S, Sawai K, Takeuchi Y, Iwayama H, Ishikawa H, Ohsumi S \& Fukui Y 2004 Interspecies somatic cell nuclear transfer for in vitro production of Antarctic minke whale (Balaenoptera bonaerensis) embryos. Cloning and Stem Cells 6 284-293. (doi:10.1089/clo.2004.6.284)

Koehler D, Zakhartchenko V, Froenicke L, Stone G, Stanyon R, Wolf E, Cremer T \& Brero A 2009 Changes of higher order chromatin arrangements during major genome activation in bovine preimplantation embryos. Experimental Cell Research 315 2053-2063. (doi:10.1016/ j.yexcr.2009.02.016)

Kwon DK, Kang JT, Park SJ, Gomez MN, Kim SJ, Atikuzzaman M, Koo OJ, Jang G \& Lee BC 2011 Blastocysts derived from adult fibroblasts of a rhesus monkey (Macaca mulatta) using interspecies somatic cell nuclear transfer. Zygote 19 199-204. (doi:10.1017/s0967199411000232)

Lee C, Wevrick R, Fisher RB, Ferguson-Smith MA \& Lin CC 1997 Human centromeric DNAs. Human Genetics 100 291-304. (doi:10.1007/ s004390050508)

Lehmann G 2006 Kappa Sigma Clipping. The Insight Journal http://hdl. handle.net/1926/367.

Lehmann G, Pincus Z \& Regrain B 2006 Wrap ITK: Enhanced languages support for the Insight Toolkit. The Insight Journal http://hdl.handle.net/ 1926/188.
Lorthongpanich C, Laowtammathron C, Chan AW, Ketudat-Cairns M \& Parnpai R 2008 Development of interspecies cloned monkey embryos reconstructed with bovine enucleated oocytes. Journal of Reproduction and Development 54 306-313. (doi:10.1262/jrd.20049)

Maalouf WE, Liu Z, Brochard V, Renard JP, Debey P, Beaujean N \& Zink D 2009 Trichostatin A treatment of cloned mouse embryos improves constitutive heterochromatin remodeling as well as developmental potential to term. BMC Developmental Biology 911. (doi:10.1186/1471-213X-9-11)

Manes C 1973 The participation of the embryonic genome during early cleavage in the rabbit. Developmental Biology 32 453-459. (doi:10.1016/0012-1606(73)90254-6)

Martin C, Beaujean N, Brochard V, Audouard C, Zink D \& Debey P 2006 a Genome restructuring in mouse embryos during reprogramming and early development. Developmental Biology 292 317-332. (doi:10.1016/ j.ydbio.2006.01.009)

Martin C, Brochard V, Migne C, Zink D, Debey P \& Beaujean N $2006 b$ Architectural reorganization of the nuclei upon transfer into oocytes accompanies genome reprogramming. Molecular Reproduction and Development 73 1102-1111. (doi:10.1002/mrd.20506)

Mayer W, Smith A, Fundele R \& Haaf T 2000 Spatial separation of parental genomes in preimplantation mouse embryos. Journal of Cell Biology $\mathbf{1 4 8}$ 629-634. (doi:10.1083/jcb.148.4.629)

Memili E \& First NL 1999 Control of gene expression at the onset of bovine embryonic development. Biology of Reproduction 61 1198-1207. (doi:10.1095/biolreprod61.5.1198)

Merico V, Barbieri J, Zuccotti M, Joffe B, Cremer T, Redi CA, Solovei I \& Garagna S 2007 Epigenomic differentiation in mouse preimplantation nuclei of biparental, parthenote and cloned embryos. Chromosome Research 15 341-360. (doi:10.1007/s10577-007-1130-5)

Miller OJ \& Therman E 2000 Human Chromosomes. New York: Springer.

Park SH, Shin MR \& Kim NH 2004 Bovine oocyte cytoplasm supports nuclear remodeling but not reprogramming of murine fibroblast cells. Molecular Reproduction and Development 68 25-34. (doi:10.1002/mrd. 20050)

Pichugin A, Le Bourhis D, Adenot P, Lehmann G, Audouard C, Renard JP, Vignon X \& Beaujean N 2010 Dynamics of constitutive heterochromatin: two contrasted kinetics of genome restructuring in early cloned bovine embryos. Reproduction 139 129-137. (doi:10.1530/ REP-08-0435)

Probst AV, Santos F, Reik W, Almouzni G \& Dean W 2007 Structural differences in centromeric heterochromatin are spatially reconciled on fertilisation in the mouse zygote. Chromosoma 116 403-415. (doi:10.1007/s00412-007-0106-8)

Probst AV, Okamoto I, Casanova M, El Marjou F, Le Baccon P \& Almouzni G 2010 A strand-specific burst in transcription of pericentric satellites is required for chromocenter formation and early mouse development. Developmental Cell 19 625-638. (doi:10.1016/j.devcel. 2010.09.002)

Reis Silva AR, Adenot P, Daniel N, Archilla C, Peynot N, Lucci M, Beaujean N \& Duranthon V 2011 Dynamics of DNA methylation levels in maternal and paternal rabbit genomes after fertilization. Epigenetics 6 987-993. (doi:10.4161/epi.6.8.16073)

Sansinena MJ, Reggio BC, Denniston RS \& Godke RA 2002 Nuclear transfer embryos from different equine cell lines as donor karyoplasts using the bovine oocyte as recipient cytoplast. Theriogenology 58 775-777. (doi:10.1016/S0093-691X(02)00745-8)

Santenard A, Ziegler-Birling C, Koch M, Tora L, Bannister AJ \& TorresPadilla ME 2010 Heterochromatin formation in the mouse embryo requires critical residues of the histone variant H3.3. Nature Cell Biology 12 853-862. (doi:10.1038/ncb2089)

Scheübeler D, Francastel C, Cimbora DM, Reik A, Martin DI \& Groudine M 2000 Nuclear localization and histone acetylation: a pathway for chromatin opening and transcriptional activation of the human $\beta$-globin locus. Genes and Development 14 940-950. (doi:10.1101/gad.14.8.940)

Shaw PJ, Abranches R, Paula-Santos A, Beven AF, Stoger E, Wegel E \& Gonzalez-Melendi P 2002 The architecture of interphase chromosomes and nucleolar transcription sites in plants. Journal of Structural Biology 140 31-38. (doi:10.1016/S1047-8477(02)00537-3) 
Skok JA, Brown KE, Azuara V, Caparros ML, Baxter J, Takacs K, Dillon N, Gray D, Perry RP, Merkenschlager M et al. 2001 Nonequivalent nuclear location of immunoglobulin alleles in B lymphocytes. Nature Immunology 2 848-854. (doi:10.1038/ni0901-848)

Solovei I, Schermelleh L, During K, Engelhardt A, Stein S, Cremer C \& Cremer T 2004 Differences in centromere positioning of cycling and postmitotic human cell types. Chromosoma 112 410-423. (doi:10.1007/ s00412-004-0287-3)

Song BS, Lee SH, Kim SU, Kim JS, Park JS, Kim CH, Chang KT, Han YM, Lee KK, Lee DS et al. 2009 Nucleologenesis and embryonic genome activation are defective in interspecies cloned embryos between bovine ooplasm and rhesus monkey somatic cells. BMC Developmental Biology 9 44. (doi:10.1186/1471-213X-9-44)

Vissel B \& Choo KH 1989 Mouse major (gamma) satellite DNA is highly conserved and organized into extremely long tandem arrays: implications for recombination between nonhomologous chromosomes. Genomics 5 407-414. (doi:10.1016/0888-7543(89)90003-7)
Wang K, Beyhan Z, Rodriguez RM, Ross PJ, lager AE, Kaiser GG, Chen Y \& Cibelli JB 2009 Bovine ooplasm partially remodels primate somatic nuclei following somatic cell nuclear transfer. Cloning and Stem Cells $\mathbf{1 1}$ 187-202. (doi:10.1089/clo.2008.0061)

Weierich C, Brero A, Stein S, Von Hase J, Cremer C, Cremer T \& Solovei I 2003 Three-dimensional arrangements of centromeres and telomeres in nuclei of human and murine lymphocytes. Chromosome Research 11 485-502. (doi:10.1023/A:1025016828544)

Received 4 November 2012

First decision 1 December 2012

Revised manuscript received 29 November 2012

Accepted 5 December 2012 